\title{
Implications of Covid-19 in ophthalmology
}

\section{Implicações do Covid-19 na oftalmologia}

\author{
André Luiz Netto Pereira' ${ }^{1}$ https://orcid.org/0000-0002-5793-0124 \\ Felipe Ornell² https://orcid.org/0000-0002-3881-4283 \\ Juliana Nichterwitz Scherer ${ }^{3}$ https://orcid.org/0000-0002-9235-0416 \\ Cassiano Innocente ${ }^{4}$ https://orcid.org/0000-0003-4676-181X
}

\begin{abstract}
'Serviço de Oftalmologia, Hospital Nossa Senhora da Conceição, Porto Alegre, RS, Brasil. ${ }^{2}$ Hospital de Clínicas de Porto Alegre, Universidade Federal do Rio Grande do Sul, Porto Alegre, RS, Brasil. ${ }^{3}$ Universidade do Vale do Rio dos Sinos, São Leopoldo, RS, Brasil.

${ }^{4}$ Hospital Nossa Senhora da Conceição, Porto Alegre, RS, Brasil.

Os autores não possuem conflitos de interesse
\end{abstract}

Recebido para publicação em 29/3/2020 - Aceito para publicação em 6/5/2020

The Covid- 19 Pandemy has brought several challenges to the health care systems throughout the planet, since it requires complex strategies and public policies of contention, diagnosis and treatment. Especifically, the high transmissibility of the virus is a critical point of the pandemy, which turns the medical teams highly vulnerable. ${ }^{(1-3)}$

Initially, the transmission of the disease via the eye was ignored and ophthalmology was not considered a specialty under risk. ${ }^{(4,5)}$ The case of contamination of Dr Wang Guangfa, during the treatment of patients with Covid-19, however, altered the scenario, once the infection via eye was raised as a hypothesis, in light of the fact that the professional had worn PPEs, except glasses. ${ }^{(6)}$

Recently, this hypothesis has gained scientific support with basis in the publishing of The Lancet, which highlighted that the ocular surface may be a possible means of transmission. This fact can be explained by the contamination potential of the conjunctival epithelium through contact with infectious droplets and contaminated body fluids. ${ }^{(4)}$ Besides this, another investigation has suggested that the virus can disseminate after droplets contact from the conjunctiva to the respiratory tract through the nasolacrimal duct. ${ }^{(7)}$ Moreover, there are indications that the virus can be detected in the tear and in conjunctival secretions of patients diagnosed with Covid - 19 and conjunctivitis. This is in alignment with previous studies that evaluate other kinds of coronavirus in humans and animals. ${ }^{(8,9)}$ However, the infection by this means has not been elucidated. ${ }^{(6,9)}$

These findings signal two pertinent issues to opthamologists: 1) The relation between Covid - 19 and the eye, (ways of contamination, clinical implications...) needs to be investigated more precisely, specially due to the potential development of diagnosis mechanisms based on ocular secretions; 2) The urgency in the implementation of safety protocols in ophthalmology services.

Infection Control Measures described by the law and by employees may help the establishment of guidelines to reduce the risk of infection by Covid - 19. Initially, the triage of patients must be established to identify patients with fever, respiratory symptoms (mainly dyspnea), cough and acute conjunctivitis. Furthermore, procedures that may generate micro aerosols must be avoided, as tonometries without contact and elective surgeries under general anesthesia. Protection shields must be installed on slit lamps and disinfection of the equipment and of the rooms must be done frequently. PPEs to protect the mouth, the nose ( mask $\mathrm{N}-95$ ) and the eyes (eye protection goggles or face shield mask) when seeing patients potentially infected. Lastly, the frequent hand sanitization and respiratory etiquette must be stimulated. ${ }^{(10)}$

It is highlighted that although symptomatic patients are twice more contagious, the asymptomatic are six times more frequent. (11) In this regard, the possibility of contact with contaminated patients may go unnoticed due to the absence of symptoms in ophthalmological appointments. Thus, it is vitally important that these protection measures be implemented not only in hospital level but also outpatient.

In Brazil, where the disease is in exponential expansion, there are not any publications in scientific journals regarding Covid- 19 under the Ophthalmology standpoint. We hope that this paper serves as an alert to the need of protection and the use of PPEs during ophthalmological appointments, specially routine check-ups, as well as being starting point for new researches, since this matter's appropriation is of utter urgency and it is vital that there are more investigations carried out.

\section{RefERENCES}

1. World Health Organization (WHO). WHO. Novel Coronavirus (2019-nCoV) situation reports. Geneva:WHO; 2020.

2. Cascella M, Rajnik M, Cuomo A, Dulebohn SC, Di Napoli R. Features, evaluation and treatment coronavirus (COVID-19). Treasure Island (FL): StatPearls; 2020.

3. [The epidemiological characteristics of an outbreak of 2019 novel coronavirus diseases (COVID-19) in China]. Zhonghua Liu Xing Bing Xue Za Zhi. 2020;41(2):145-51. Chineese.

4. Lu CW, Liu XF, Jia ZF. 2019-nCoV transmission through the ocular surface must not be ignored. Lancet. 2020;395(10224):e39.

5. Huang C, Wang Y, Li X, Ren L, Zhao J, Hu Y, et al. Clinical features of patients infected with 2019 novel coronavirus in Wuhan, China. Lancet. 2020;395(10223):497-506.

6. Li JO, Lam DSC, Chen Y, Ting DSW. Novel Coronavirus disease 2019 (COVID-19): The importance of recognising possible early ocular manifestation and using protective eyewear. Br J Ophthalmol. 2020;104(3):297-8.

7. Qing H, Li Z, Yang Z, Shi M, Huang Z, Song J, et al. The possibility of COVID-19 transmission from eye to nose. Acta Ophthalmol. 2020;10.1111/aos.14412.
8. Seah I, Agrawal R. Can the coronavirus disease 2019 (COVID-19) affect the eyes? A review of coronaviruses and ocular implications in humans and animals. Ocul Immunol Inflamm. 2020;28(3):391-5.

9. Xia J,Tong J, Liu M, Shen Y, Guo D. Evaluation of coronavirus in tears and conjunctival secretions of patients with SARS-CoV-2 infection. J Med Virol. 2020;92(6):589-94.

10. Lai TH, Tang EW, Chau SK, Fung KS, Li KK. Stepping up infection control measures in ophthalmology during the novel coronavirus outbreak: an experience from Hong Kong. Graefes Arch Clin Exp Ophthalmol. 2020;258(5):1049-55.

11. Li R, Pei S, Chen B, Song Y, Zhang T, Yang W, et al. Substantial undocumented infection facilitates the rapid dissemination of novel coronavirus (SARS-CoV2). Science. 2020;eabb3221.

Autor correspondente

André Luiz Netto Pereira

E-mail: anluizp@gmail.com

Telefone (51)99947-5175 